\title{
Thrombocytopenia, an Overlooked Hematological Derangement in Hair Dye Poisoning
}

\author{
Rizwan Naseer ${ }^{1}$, AliRaza Ghani ${ }^{2}$ \\ ${ }^{1}$ King Edward Medical University, Lahore, Pakistan \\ ${ }^{2}$ Abington Jefferson Health System, Abington, PA, USA \\ Email: rizwannaseer369@gmail.com
}

Received 23 June 2015; accepted 7 August 2015; published 10 August 2015

Copyright (C 2015 by authors and Scientific Research Publishing Inc.

This work is licensed under the Creative Commons Attribution International License (CC BY). http://creativecommons.org/licenses/by/4.0/

(c) (i) Open Access

\begin{abstract}
Thrombocytopenia is a common hematological disorder characterized by abnormally low number of platelets in circulating blood from multiple causes. The fundamental mechanisms involved are: ineffective production of platelets by the bone marrow, accerlated destruction of platelets or platelet splenic sequestration. Hair dye, containing Paraphenyllinediamaine has been linked to allergic reaction, nephrotoxicity, mutagenicity and hematological derangements as anemia. $\mathrm{A}$ female showed a clinical spectrum of decreasing platelet count along with anemia due to oral ingestion of hair dye. It is important to consider thrombocytopenia in management plan as it may impact the clinical outcome.
\end{abstract}

Keywords

Hair Dye, Poisoning, PPD, Thrombocytopenia, Kala Pathar

\section{Introduction}

Hair dye, also known as "Kala Pathar", is increasingly common mode of poisoning with suicidal intent in developing countries like Pakistan due to its easy availability and cost effectiveness. Number of cases presenting to ER is on rise with every coming year. PPD (Paraphenylline Diamine) and related compounds are common constituent of all commercially available hair dyeing products and their toxic effects on human body, both by chronic topical application and oral ingestion, are well established [1]. Oral ingestion of hair dye has varied clinical manifestation due to allergenic, mutagenic and direct corrosive effect of PPD. The commonly reported and observed spectrum, which depends on the amount of dye ingested,ranges from angioedema, intravascular 
hemolysis, renal failure, rhabdomyolysis, metabolic acidosis, myocarditis and arrhythmias. PPD is a coal tar derivative and produces a base on oxidation called Bondrowski's base which exerts the toxic reaction [2]. Platelets or thrombocytes are one of the cellular elements of blood which have widely established function in hemostasis. Lower counts in peripheral blood can lead to bleeding episodes, ranging from minor bleeds to life threatening one.

A normal human platelet count ranges from 150,000 to 400,000 per microliter of blood. The exact mechanisms involved in thrombocytopenia due to PPD has not been studied or reported but appears to be the combination of direct toxic effect to platelets leading to their accerlated killing and effect on bone marrow leading to ineffective or suppressed production. Hair dye has a toxic effect on the bone marrow and suppresses the formation of cellular elements of blood as reported in many case reports [3] [4]. In this report we present the pattern of platelet count changes observed and emphasize the clinicians to keep an eye on platelet count during active treatment and follow up period to improve the clinical outcome.

\section{Case Report}

A 15 year old female presented to emergency 10 hours after ingesting unknown amount of hair dye with difficulty breathing, facial swelling and burning sensation in throat for last 8 - 9 hours. On examination she was in respiratory distress with rate of $24 / \mathrm{min}$, BP $100 / 80 \mathrm{mmhg}$ and pulse of $94 / \mathrm{min}$. She had facial edema, swelling of lips and stridor. She was admitted in ICU, given iv fluids, steroids, chlorpheniramine and emergency tracheostomy was performed to secure her airway.

Initial labs showed ABG PH 7.37 $\mathrm{PaCO}_{2} 28.6 \mathrm{PaO}_{2} 91.5 \mathrm{HCO}_{3} 16.2 \mathrm{CBC} \mathrm{HB} 10.5$ WBC 14.2 HCT 31.5\% PLT 231 AST 199 ALT 188.

Patient was kept in ICU with supportive treatment and she improved clinically, but her platelet count kept on falling with every advancing day. Patient was discharged home due to clinical improvement and later followed by serial CBC on outpatient basis which showed persistent thrombocytopenia, but fortunately no clinical evidence of bleeding was noticed. Subsequent platelet counts and labs from same patient are shown in Table 1.

\section{Discussion}

The case presented illustrates that thrombocytopenia is a common manifestation of PPD poisoning and should be kept an eye upon along with other more obvious and reported hematological derangements as hemolytic

\begin{tabular}{|c|c|c|c|c|c|}
\hline Timeline & Platelet count & $\mathrm{HB} g / \mathrm{dl}$ & ALT U/L & AST U/L & $\mathrm{CK} \mathrm{U/L}$ \\
\hline Day 1 & 231 & 12.4 & 188 & 199 & 3343 \\
\hline Day 2 & 273 & 14 & 478 & 516 & 3313.7 \\
\hline Day 3 & 183 & 10.3 & 492 & 552 & 3674 \\
\hline Day 4 & 131 & 10.3 & 774.6 & 871 & 2892.3 \\
\hline Day 5 & 98 & 10.5 & 972.5 & 1031.3 & 2985 \\
\hline Day 6 & 56 & 12.7 & 454 & 764 & 2384 \\
\hline Day 7 & 44 & 11.7 & 76 & 83 & 2967.4 \\
\hline Day 8 & 16 & 12.1 & 387.0 & 126.9 & 2657.7 \\
\hline Day 9 & 68 & 11.5 & 263 & 67 & 1558.3 \\
\hline Day 10 & 195 & 12.9 & 192 & 61 & 1004.0 \\
\hline Day 11 & 248 & 12.5 & 158 & 48 & 526.2 \\
\hline Day 12 & 172 & 12.7 & 127.4 & 39.6 & 474.8 \\
\hline Day 13 & 156 & 11.4 & 64 & 30.7 & 171 \\
\hline
\end{tabular}


anemia. Topical application of PPD has been reported to be linked to allergic reactions, aplastic anemia, peripheral neuropathy and breast cancer [5] [6]. The oral ingestion of hair dye appears more brutal and acutely life threatening. During clinical course of PPD poisoning, which yet has no specific clinical spectrum, thrombocytopenia must be kept in view during treatment and follow-up to prevent worse clinical outcome. The most common manifestations leading to mortality in PPD poisoning are respiratory failure due to angioedema, renal failure requiring dialysis and cardiac rhythm disturbances [7] [8]. None of these causes have been dose stratified as the amount ingested is mostly unknown in patient with suicidal ingestion. So, the clinician dealing with case have prime focus on maintaining airway patency, renal check and cardiac status. But in patients who ingested low dose of PPD or ingestion followed immediately by vomiting, low dose reach systemic circulation and the entire reported spectrum may not be evident. Thrombocytopenia should be the one to keep an eye on patient who successfully avoided the worse event from renal, cardiac and respiratory dysfunction during active management phase in ICU. Serial platelet counts should be obtained on follow up at least for two weeks. This phenomenon may prove to be more beneficial in geriatric population with many co morbidities and low platelet count may lead to worse event as bleeding.

In this typical patient major concern was respiratory distress as patient presented with difficulty breathing and early tracheostomy was done to maintain airway patency. Later the clinical course was complicated by rhabdomyolysis which responded to adequate management. Platelet count showed a drop and later patient was discharged and followed on outpatient basis with serial platelet counts. Fortunately patient was kept on keen follow up and no adverse event as bleeding from any site was noted. This thing should be more emphasized in a patient who seemingly or reportedly consumed a large amount of dye or in patients whom follow up is not certain. It's very reasonable to keep those patients indoor or in close observation to review their daily platelet counts and clinical evidence of bleeding.

\section{Conclusion}

The systemic effects of PPD poisoning are many after oral ingestion and can lead to death. The exact lethal dose and dose related manifestations have not been reported as studies are lacking. In clinical course of PPD poisoning, thrombocytopenia should be kept an eye on and monitored during the following up period to prevent worse event as bleeding in otherwise doing good patient.

\section{Conflict of Interest}

All authors have no any actual or potential conflict of interest including financial, personal or other relationships with other people or organization within three years of beginning of submitted work that can inappropriately influence, or be perceived to influence, our work.

\section{Submission Declaration and Verification}

We also declare that the work described has not been published previously except in the form of an abstract or as part of a published lecture or academic thesis or as an electronic preprint, is approved that, if accepted, it will not be published elsewhere in the same form, in English or in any other language, including electronically without the written consent of the copyright-holder.

\section{Authorship}

Rizwan Naseer was the principal researcher and prepared the first draft of the report. AliRaza Ghani edited and reviewed the article.

\section{References}

[1] Patra, A.P., Shaha, K.K., Rayamane, A.P., Dash, S.K., Mohanty, M.K., et al. (2015) Paraphenylenediamine Containing Hair Dye: An Emerging Household Poisoning. American Journal of Forensic Medicine \& Pathology, in press. http://dx.doi.org/10.1097/PAF.0000000000000165

[2] Sampathkumar, K. and Yesudas, S. (2009) Hair Dye Poisoning and the Developing World. Journal of Emergencies, Trauma, and Shock, 2, 129-131. http://dx.doi.org/10.4103/0974-2700.50749

[3] Hopkins, J.E. and Manoharan, A. (1985) Severe Aplastic Anaemia Following the Use of Hair Dye: Report of Two 
Cases and Review of Literature. Postgraduate Medical Journal, 61, 1003-1005. http://dx.doi.org/10.1136/pgmj.61.721.1003

[4] Burnett, C.M., Corbett, J.F. and Lanman, B.M. (1977) Hair Dyes and Aplastic Anemia. Drug and Chemical Toxicology, 1, 45-61. http://dx.doi.org/10.3109/01480547709034426

[5] Burnett, C.M. and Menkart, J. (1979) Hair Dye Use and Breast Cancer. Journal of the National Cancer Institute, 62, 1327-1328.

[6] Deeb, W., Cachia, D., Quinn, C. and Salameh, J. (2014) Peripheral Neuropathy after Hair Dye Exposure: A Case Report. Journal of Clinical Neuromuscular Disease, 15, 161-163. http://dx.doi.org/10.1097/CND.0000000000000032

[7] Kaballo, B.G., Khogali, M.S., Khalifa, E.H., Khaiii, E.A., Ei-Hassan, A.M., et al. (2007) Patterns of "Severe Acute Renal Failure” in a Referral Center in Sudan: Excluding Intensive Care and Major Surgery Patients. Saudi Journal of Kidney Diseases and Transplantation, 18, 220-225.

[8] Brahmi, N., Kouraichi, C., Blel, Y., Mourali, S., Thabet, H., et al. (2006) Acute Myocarditis and Myocardial Infarction Induced by Paraphenylenediamine Poisoning. Interest of Angiocoronarography. International Journal of Cardiology, 113, E93-E95. http://dx.doi.org/10.1016/j.ijcard.2006.05.034 